\title{
Soil-water resistivity curve of a tropical soil
}

\author{
Thiago de Souza Carnavale ${ }^{1,2, *}$, Ana Carolina de Campos Viana ${ }^{1}$, Paula Morais Canedo de Magalhães ${ }^{1}$, \\ and Tácio Mauro Pereira de Campos ${ }^{1}$ \\ ${ }^{1}$ Civil Engineering Department, Pontifical Catholic University of Rio de Janeiro (PUC-Rio) - Brazil \\ ${ }^{2}$ Civil Engineering, Centro Universitário Serra dos Órgãos (UNIFESO) - Brazil
}

\begin{abstract}
The evaluation of soil-water characteristic curve is one of the most important procedures in the matter of understanding the soil behaviour during wetting and drying processes. Even though it might be carried out by established methods, this practice is considered a time-consuming technique, and because of this it is still under-used in comparison with its potential applications. In this way, this paper aims to analyse the correlation of soil suction and soil resistivity to produce a time-reduced soil-water characteristic curve (SWCC), based on resistivity measured values. To perform this research, it was used a set of soil samples collected from Nova Friburgo, Rio de Janeiro - Brazil. The material was geotechnically characterized by standard methods. To determine the (SWCC), it was used the filter paper method and the volumetric water content/suctions were obtained by wetting and drying stages for two paths that emerged from the field moisture content. The results revealed a remarkable relationship between suction and the resistivity measured data, emphasizing the feasibility of determining the Soil-Water Characteristic Curve by resistivity measurements, here named Soil-Water Resistivity Curve (SWResC).
\end{abstract}

\section{Introduction}

Currently, the unsaturated properties of the soils are increasingly being demanded by researchers. Since the saturated analysis are not able to depict the entire relationship between the positive and negative pore water pressure of the soils in its natural conditions, the ability to retain water at different moisture levels, described by the soil-water characteristic curve (SWCC), is pointed out as a relevant subject recognized by a standard method, and referred by several papers [1-4].

As far as determining the soil-water characteristic curve is concerned, one of the main techniques is the filter paper method (ASTM D5298 - 16) [5]. The procedure is based on the suction's equilibrium principle, in which two porous materials, when placed in contact, will lose, and absorb water until achieving the equilibrium of suction.

However, even being considered as the simplest method to determine the relation between moisture and suction of the soil, the equilibrium of suction is the major factor responsible by operational limitations regarding its time-consuming characteristic. It happens because the stabilization time varies according to the level of suction measured and may vary from 7 to 30 days [6-7]. Thus, regarding this delay in obtaining the results, this technique is still under-used and complementary procedures are currently emerging from theoretical and experimental research [8-10] to obtain the SWCC in a reduced time.

Considering the resistivity and the capillarity pressure of unsaturated soils have certain characteristics in common, such as dependence of structure and heterogeneity of the materials, a promising approach is to obtain a reliable SWCC by measuring soil resistivity (based on the British Standard Method - 1377-3:2018) [11].

The use of the technique has been presented by laboratory and field results that point out a noteworthy relationship between resistivity values and gravimetric moisture content [12-14]. In addition, tests that measure the resistivity of soils are considered much practical than techniques as the filter paper method because they are easier to perform and because there is no dependence of equilibrium time.

Although, until now it is not known how to estimate suction from resistivity accurately, the relationship between the moisture, suction, and resistivity is still requiring for correlations that can reveal remarkable information about drying and wetting cycles. Regarding this, the current research aims to evaluate the soil suction and the resistivity values for the unsaturated soil samples tested under different moisture content.

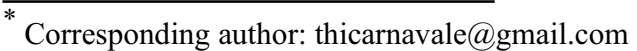


The soil used in the tests have been sampled from the Condomínio do Lago - Nova Friburgo, under coordinates $\left(42^{\circ} 38^{\prime} 32.45^{\prime \prime} \mathrm{O} ; 22^{\circ} 14^{\prime} 5.55^{\prime \prime} \mathrm{S}\right)$. The area is geographically positioned in the mountainous region of Rio de Janeiro state, in the reverse of the escarpment of the Serra dos Órgãos. The site is comprised of several steep slopes of soils and rocks. In addition, its heavy rainfall predisposition is also responsible to depict a high-risk scenario when it comes to the anthropogenic occupation.

As a proof of the high-risk content of the place is that, in January of 2011, under extreme weather conditions, the entire mountainous region was affected by one of the most important disasters of the Brazilian history. In that case, the event named "Megadesastre da Serra" caused more than 900 deaths as consequence of hundreds of landslides [15].

The Condomínio do Lago was seriously injured by a massive landslide that exposed a planar failure on the interface between the young and mature residual soils. The event was responsible to destroy 18 houses and caused relevant damages in other 23 properties.

The geologic patterns analysed at the failure surface area exposed a granite-gneiss soil placed on a tectonic fault. The fault was filled up by materials considered responsible to reduce the permeability of the layers, creating a contrast between two horizons of soils. These geological frames and the slope morphology concentrated the water flow into the mature horizon, increasing the pore water pressure, causing the failure [16].

\section{Resistivity}

In order to introduce the resistivity concept, the Ohm's law (Equation 1) might be brought to the light, since the relation between current, voltage and resistance is described as a product of the difference of potential electric of a given material. Thus, the electrical resistance $(R)$ is a physical quantity that represents the impediment to the passage of an electric current through a given body (conductor), subjected to a potential difference.

$$
U=R * i
$$

Where:

$U$ is the voltage;

$R$ is the resistance;

and $i$ is the current.

There are two types of conductors (resistors), described as Ohmics and non-Ohmics. The difference is related to its response in terms of resistance to a constant temperature condition. The law points out the voltage can be directly correlated to the current if the temperature is held constant into a specified range. Since this rule is broken, the conductor is named non-Ohmic.
Another concept that can be introduced to the readers is the electrical conductivity. It is the opposite of resistivity [17]. In broad terms, it is the capacity of a given material to conduct electrical energy. Its main unit is Siemens per meter $(\mathrm{S} / \mathrm{m})$.

Further, the concept of resistivity is not the same as resistance. Resistivity is described as the resistance per unit volume and is considered a bulk property of the materials [18]. Resistivity $(\rho)$ is also related to the impediment to the passage of an electric current. However, resistivity is an intrinsic magnitude of the material, not depending on body size/volume. Further, this electric current quantity depends on the dimensions of the body and the type of material.

Regarding soils, the concepts conductivity and resistivity must be understood in the light of soil's mineral composition, its cation exchange capacity, the structural arrangement, and the water content. Thus, several factors will affect the results achieved by the Ohm's Law. In complement, the air disposed in the voids acts as an insulator (i.e., infinitively resistive). The water solution conductivity is a function of the ionic concentration, and the resistivity of the solid grains is also related to the electrical charge's density at the surface of the constituents.

Electrical resistivity experiments have been performed to establish relationships between the electrical resistance and the soil characteristics aforementioned [19]. As a relevant research concerned with soil resistivity is the global model described by McNeill [20]. The author summarized typical values for apparent resistivity for various thawed materials using three measuring techniques (Table 1). At that time, it was also described the correlation between the resistivity values of soils in different climatic zones of the planet and highlighted the moisture content of the soils disposed in humid areas is connected to higher values of conductivity and low values of resistivity.

Table 1. Resistivity - Typical values for soils and rocks (McNeill, 1980).

\begin{tabular}{cc}
\hline \multicolumn{2}{c}{ Apparent Resistivity } \\
Soil & Ohm $/ \mathrm{m}$ \\
\hline Granite - Canaan & $2000-20000$ \\
Sand - Hanover & $250-10000$ \\
Silty Sand - Toronto/Ontario & $50-4000$ \\
Sandy Silt - Toronto/Ontario & $50-1200$ \\
Silt - Fairbanks (Glennck) & $160-1800$ \\
Silt - Fairbanks (Field Station) & $40-100$ \\
Silt - Fairbanks (Goldstream) & $55-550$ \\
Silty Clay - Gulkana & $20-90$ \\
Clay - Lebanon & $15-180$ \\
\hline
\end{tabular}


In addition, Palacky [21] revealed a set of results for Brazilian tropical soils emphasizing a quite correlation between the soil resistivity and the resistivity of its parent rock.

In the matter of unsaturated soils, since it is composed of three phases (solids, water, and air) and the most conductive part is the liquid phase [22]. In this way, some research [23 - 24] studied the relationship between resistivity and moisture content, concluding that the lower the degree of saturation refers to the higher resistivity.

In granular soils, mainly composed of sand and gravel, the main element of electrical conductivity is the water contained in the pores, since quartz is a nonconductive mineral. However, concerning clay soils, conductivity is also related to the electrical charges present on clay mineral surfaces. Furthermore, the void index influences the passage of electric current in unsaturated soils because the resistivity will be higher, since lower is the material void index, for the same degree of saturation.

The resistivity of soil is obtained by measuring the resistance to the passage of a known electrical current created by imposing a difference of potential electric between two points in the soil. Thus, for soil with given moisture content, the amperage (current) reading is taken for various moisture levels, undercovering the resistivity results based on the water content of the soil, here named Soil-Water Resistivity Curve (SWResC).

\section{Materials and methods}

\subsection{Soil characterisation}

In order to evaluate the mineral composition of the soil, a microscopic observation was performed, and the results revealed that the granular texture is composed essentially by quartz, feldspar, oxides of iron and manganese.

Additionally, the undisturbed samples of soil were collected at $50 \mathrm{~cm}$ of depth and was characterized based on the NBR-6457 [25], and NBR-6458 [26]. The results are presented in Table 2 .

Table 2. Soil properties.

\begin{tabular}{cc}
\hline Specific Gravity - Gs & 2.66 \\
$\gamma \mathrm{d}\left(\mathrm{kN} / \mathrm{m}^{3}\right)$ & 13.20 \\
Void ratio - e & 0.71 \\
Saturation Degree $-\mathrm{S}(\%)$ & 48.8 \\
\hline
\end{tabular}

The Grain Size Distribution was determined by sieving and hydrometer methods based on the NBR7181 [27] (Table 3).
Table 3. Grain-size distribution resume.

\begin{tabular}{cc}
\hline Gravel (\%) & 4.28 \\
Sand (\%) & 50.23 \\
Silt (\%) & 16.04 \\
Clay (\%) & 29.45 \\
\hline Liquid Limit (\%) & 42.30 \\
Liquid Limit (\%) & 30.70 \\
Plasticity Index (\%) & 11.60 \\
Activity & 0.39 \\
\hline
\end{tabular}

The Aterberg Limits revealed an inactive clay and according to the Unified Soil Classification System USCS, the material has been classified as SC - Sandclay.

The soil-water characteristic curve of the current research was based on the filter paper method [6-7] and moisture/suction values were obtained by two paths (wetting and drying). The results were plotted together with the literature survey (Figure 1).

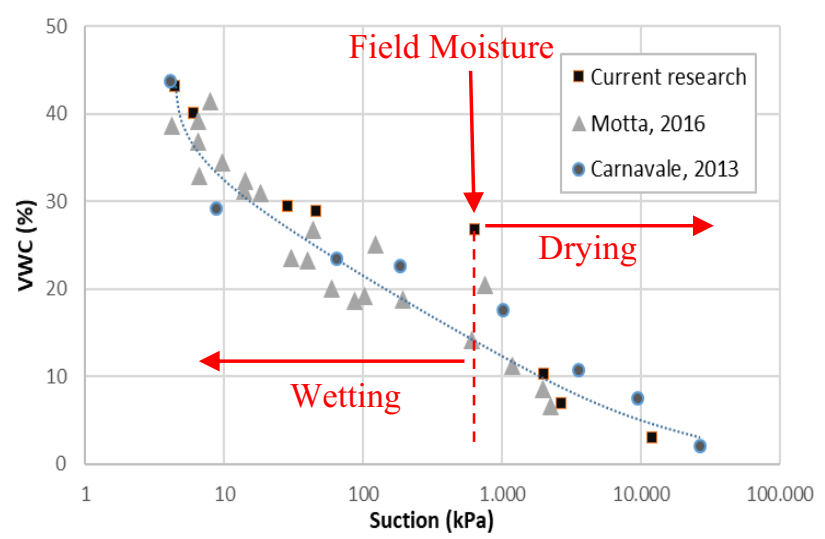

Fig. 1. Soil-water characteristic curves. Volumetric water content (VWC) vs. suction [28, 29].

The field moisture point differs from the values depicted by the literature survey. It can be related to the site characteristics, that is composed by a heterogeneous mineral composition of the granite-gneiss' soil. Further, it is important to emphasize that it was used different soil blocks for the current research procedures and the others.

\subsection{Resistivity - test preparation and execution}

This test consists of passing an electric current through a specimen and measure the resistance offered by the soil. The measurements were made for each one of the specimens used in the filter paper tests, so each specimen had a different moisture value and a known suction value.

The equipment used (Figure 2) was comprised of a variable voltage source $(0-110 \mathrm{~V})$, an ammeter, a voltmeter, and a support for the specimen with two copper poles, positioned at the base and the top of the specimen. 


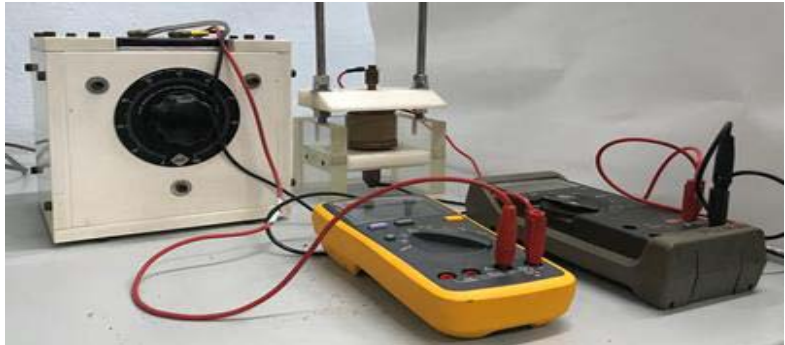

Fig. 2. Resistivity test apparatus.

After making the measures of the filter paper test, the specimen was placed in the support to measure its resistance. The procedure was performed at a constant temperature of $23{ }^{\circ} \mathrm{C}$, using a gel (for ultrasound), to improve the electrode-soil contact. The applied voltage varied at $10 \mathrm{~V}$ intervals, ranging from $10 \mathrm{~V}$ to $110 \mathrm{~V}$.

Due to losses along the wires used in the circuit, a smaller voltage value reached the specimen. Therefore, the voltage that reached the specimen was measured with the voltmeter, and this was the value used to determine resistance. For each applied voltage, the current produced was also measured. Resistivity was then calculated by Equation 2 .

$$
\rho=\frac{R * A}{L}
$$

Where:

$\rho$ is the resistivity;

$R$ is the resistance of the specimen;

$A$ is the area of the specimen;

$L$ is the length of the specimen.

It is important to emphasize that the ring used in the specimens was made of polyvinyl chloride (PVC). Thus, it was ensured that there was no transmission of electricity through the ring.

\section{Results}

The results emphasized the agreement for volumetric water content vs. suction (Figure 3), and the volumetric water content vs. resistivity (Figure 4).

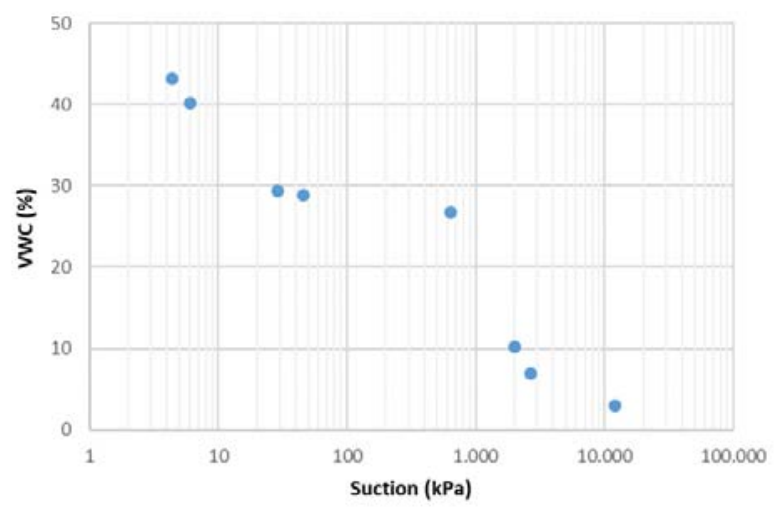

Fig. 3. Soil-water characteristic curve. Volumetric water content (VWC) vs. suction.
The resistivity and suction were compared with the volumetric water content, revealing the high accordance for the methods, especially for the lower values of volumetric water content (until 25\%). Furthermore, it is important to emphasize the initial values of resistivity is around 1000 Ohm's (due to the soil sandy composition and its structural arrangement).

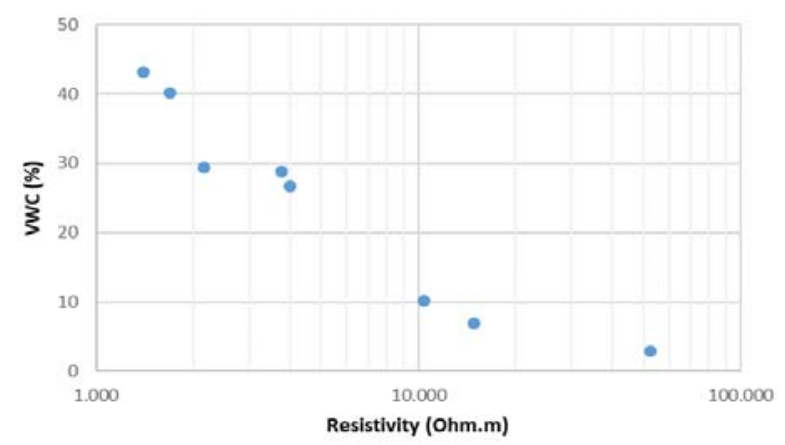

Fig. 4. Soil-Water Resistivity Curve (SWResC). Volumetric water content (VWC) vs. resistivity.

In addition, by plotting a graph that related resistivity and suction (Figure 5), was depicted a polynomial adjust that emphasizes the correlation between the measured values.

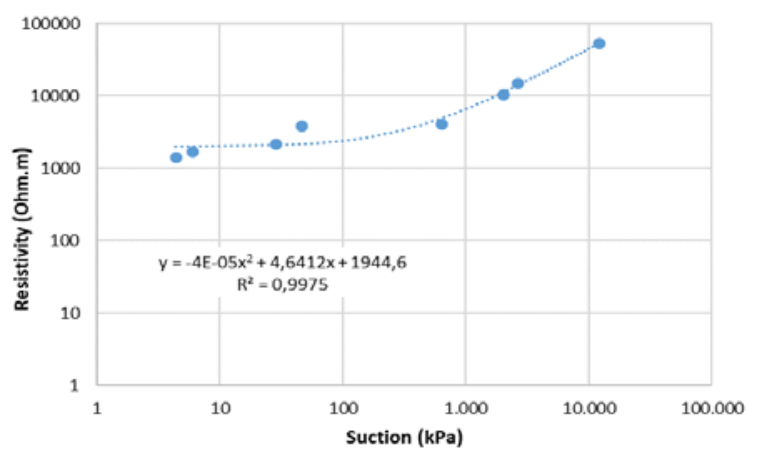

Fig. 5. Resistivity vs. suction.

The results were also plotted in a 3D graph (Figure 6) exposing the correlation of the values in the matter of determining a soil-water resistivity curve.

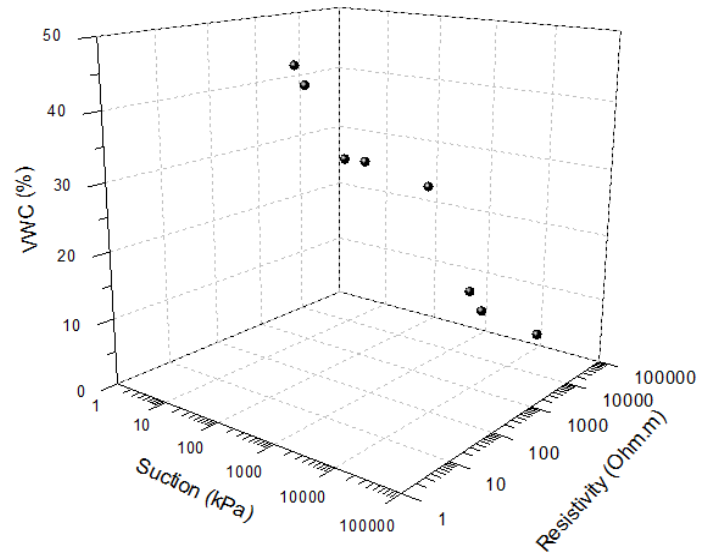

Fig. 6. 3D graph - Volumetric water content (VWC) vs. suction vs. resistivity. 


\section{Final considerations}

The results obtained in this research showed an agreement of the volumetric water content, suction, and resistivity. This affinity is especially high for values of volumetric water content under $25 \%$. In the matter of correlating resistivity and suction, it can be written as a second-order polynomial curve.

The use of resistivity is a valuable procedure as documented by the literature. The results obtained in this research emphasize the feasibility of determining the Soil-Water Characteristic Curve by resistivity measurements (depicting the Soil-Water Resistivity Curve).

As suggestions for further research is recommended to improve the database and evaluate the resistivity of different soils under the same methodology.

Acknowledgments: This research was financed by the Coordenação de Aperfeiçoamento de Pessoal de Nível Superior (Capes), Conselho Nacional de Desenvolvimento Científico e Tecnológico $(\mathrm{CNPq})$, and Fundação Carlos Chagas Filho de Amparo à Pesquisa do Estado do Rio de Janeiro (FAPERJ).

\section{References}

1. D. G. Fredlund, H. Rahardjo. (1993). Soil mechanics for unsaturated soils. New York: John Wiley \& Sons, INC.

2. D. G. Fredlund, A. Xing. (1994). Equations for the Soil-Water Characteristic Curve. Canadian Geotechnical Journal. 31, 521-532.

3. S. L. Barbour. (1998). The soil-water characteristic curve - a historical perspective and application to the behaviour of unsaturated soils. Canadian Geotechnical Journal. 35, 873-894.

4. S. K. Vanapalli, D. G. Fredlund, D. E. Pufahl. (1999). The effect of soil structure and stress history on the soil-water characteristics of a compacted till. Geotechnique. 49, No. 2, 143-159.

5. American Society for Testing and Materials. ASTM D. 5298-92. (1992). Standard test method for measurement of soil potential (suction) using filter paper. Annual Book of ASTM Standards, vol. 15.09 .

6. K. Bicalho, A. Correia, S. Ferreira, J. M. Fleureau, F. A. M. Marinho. (2007). Filter paper method of soil suction measurement.

7. F. A. M. Marinho, O. M. Oliveira. (2006). The filter paper method revisited. Geotechnical Testing Journal, 29, n. 3, p. 1-9.

8. E. Ishimwe, J. Blanchard, R. Coffman. (2018). Field-Obtained Soil Water Characteristic Curves and Hydraulic Conductivity Functions. Journal of Irrigation and Drainage Engineering. 144.

9. M. D. Fredlund, G.W. Wilson, D. G. Fredlund. (2002). Use of the grain-size distribution for estimation of the soil-water characteristic curve. Canadian Geotechnical Journal, 39, pp1103-1117.

10. W. N. Houston, H. B. Dye, C. E. Zapata, Y. Perera, A. Harraz. (2006). Determination of SWCC using one point suction measurement and standard curves. doi: 1482-1493. 10.1061/40802(189)123.

11. BS 1377-3:2018. (2018). Methods of test for soils for civil engineering purposes. Chemical and Electro-chemical Testing.

12. R Grisso, M. Alley, W. G. Wysor, D. Holshouser, W. Thomason. (2009). Precision Farming Tools: Soil Electrical Conductivity. Virginia Cooperative Extension. Precision Farming Tools: Soil Electrical Conductivity, Virginia Cooperative Extension Publication.

13. A. Mohamed, E. Paleologos. (2018). Electrical Properties of Soils. doi:10.1016/B978-0-12804830-6.00014-4

14. H. Bohn, J. Ben-Asher, H. Tabbara, M. Marwan. (1982). Theories and Tests of Electrical Conductivity in Soils1. Soil Science Society of America Journal - SSSAJ. 46. 10.2136.

15. DRM-RJ. (2011). Megadesastre da Serra. Governo do Estado do Rio de Janeiro. Rio de Janeiro, p.1889.http://www.drm.rj.gov.br/index.php/downloads/ category/13-regio-serrana.html (in Portuguese).

16. L. Lago, C. Amaral, L. E. P. Campo, L. E. Silva. (2011). Megadesastre da Serra Fluminense: o deslizamento do Condomínio do Lago, em Nova Friburgo - análise preliminar dos condicionantes geológicos. In: Simpósio de Geologia do Sudeste. Nova Friburgo, RJ. (in Portuguese).

17. A. Samouëlian, I. Cousin, A. Tabbagh, A. Bruand, R. Guy. (2005). Electrical resistivity survey in soil science: A review. Soil and Tillage Research. 83. 173-193. doi;10.1016/j.still.2004.10.004

18. F. Ozcep, O. Tezel, M. Asci. (2009). Correlation between Electrical Resistivity and Soil-Water Content: Istanbul and Golcuk. International Journal of Physical Sciences. 4. 362-365.

19. Z. Abu-Hassanein, C. Benson, L. Blotz. (1996). Electrical Resistivity of Compacted Clays. Journal of Geotechnical Engineering. 122. 397-406. doi:10.1061/(ASCE)0733-9410(1996)122:5(397)

20. J. D. McNeill. (1980). Electrical conductivity of soils and rocks (Geonics Ltd., Mississauga, Ontario, Canada, Technical Note TN-5).

21. G. Palacky. (1979). Effect of tropical weathering on electrical and electromagnetic measurements. Geophysics. 44, 69-88 doi: 10.1190/1.1440924

22. A. O. Pacheco. (2004). Resistive cone application in saturated soils, Master's dissertation, COPPE, Universidade Federal do Rio de Janeiro, 150p. (in Portuguese).

23. R. B. Boszczowski, J. M. Silva. (2006). Electrical resistivity evaluation of a residual soil profile as a function of weathering and moisture content. XIII 
COBRAMSEG, Curitiba-PR, Brazil. (in Portuguese).

24. M. T. Yamasaki, A. S. P. Peixoto, J. A. C. Ulson. (2010). Laboratory test for electrical resistivity evaluation in a sandy tropical soil. XV COBRAMSEG, Gramado - RS, Brazil. (in Portuguese).

25. Associação Brasileira de Normas Técnicas. NBR 6457. (2016). Amostras de solo "Soil samples Preparation for compaction and characterization tests" (in Portuguese).

26. Associação Brasileira de Normas Técnicas. NBR 6458. (2016). Solo "Gravel grains retained on the $4,8 \mathrm{~mm}$ mesh sieve - Determination of the bulk specific gravity, of the apparent specific gravity and of water absorption" (in Portuguese).

27. Associação Brasileira de Normas Técnicas. NBR 7181. (2016). Análise granulométrica "Grain size analysis" (in Portuguese).

28. M. F. B. Motta (2016). Caracterização FísicoHídrico-Estrutural e Efeito do Aumento da Pressão do Ar na Resistência de Solos Tropicais Não Saturados. DSc. Thesis. PUC-Rio (in Portuguese).

29. T. de S. Carnavale, (2016). Desenvolvimento de um modelo físico para a análise de efeitos de trovões em solos. Master's Thesis. PUC-Rio (in Portuguese). 